\title{
Racial and Ethnic Disparities in Graft and Recipient Survival in Elderly Kidney Transplant Recipients
}

\author{
Titilayo O. Ilori, MD, "Demilade A. Adedinsewo, MD,,$^{\dagger}$ Oluwaseun Odewole, MD, ${ }^{*}$ \\ Nosayaba Enofe, MD, *Akinlolu O. Ojo, MD, PhD, ${ }^{\S}$ William McClellan, MD, "Il and \\ Rachel E. Patzer, PhD"\|
}

OBJECTIVES: To investigate racial and ethnic differences in graft and recipient survival in elderly kidney transplant recipients.

DESIGN: Retrospective cohort.

SETTING: First-time, kidney-only transplant recipients aged 60 and older of age at transplantation transplanted between July 1996 and October 2010 ( $\mathrm{N}=$ 44,013).

PARTICIPANTS: United Network for Organ Sharing (UNOS) database.

MEASUREMENTS: Time to graft failure and death obtained from the UNOS database and linkage to the Social Security Death Index. Neighborhood poverty from 2000 U.S. Census geographic data.

RESULTS: Of the 44,013 recipients in the sample, $20 \%$ were black, 63\% non-Hispanic white, 11\% Hispanic, 5\% Asian, and the rest "other racial groups." In adjusted Cox models, blacks were more likely than whites to experience graft failure (hazard ratio $(\mathrm{HR})=1.23,95 \%$ confidence interval $(\mathrm{CI})=1.15-1.32$ ), whereas Hispanics $(\mathrm{HR}=0.77$, $95 \% \quad \mathrm{CI}=0.70-0.85)$ and Asians $(\mathrm{HR}=0.70,95 \%$ $\mathrm{CI}=0.61-0.81)$ were less likely to experience graft failure. Blacks $\quad(\mathrm{HR}=0.84, \quad 95 \% \quad \mathrm{CI}=0.80-0.88), \quad$ Hispanics $(\mathrm{HR}=0.68, \quad 95 \% \quad \mathrm{CI}=0.64-0.72), \quad$ and Asians $(\mathrm{HR}=0.62,95 \% \mathrm{CI}=0.57-0.68)$ were less likely than whites to die after renal transplantation.

CONCLUSION: Elderly blacks are at greater risk of graft failure than white transplant recipients but survive longer after transplantation. Asians have the highest recipient and graft survival, followed by Hispanics. Further studies are needed to assess additional factors affecting graft and

From the *Department of Medicine, Emory University; ${ }^{\dagger}$ Department of Medicine, Morehouse School of Medicine; 'Department of Radiology, Emory University, Atlanta, Georgia; ${ }^{\S}$ Department of Medicine, University of Michigan, Ann Arbor, Michigan; "Rollins School of Public Health; and \#Department of Surgery, School of Medicine, Emory University, Atlanta, Georgia.

Address correspondence to Titilayo O. Ilori, Renal Division, Emory University School of Medicine, 1639 Pierce Drive, Atlanta, GA 30322.

E-mail: tilori@emory.edu

DOI: $10.1111 /$ jgs. 13845 recipient survival in elderly adults and to investigate outcomes such as quality of life. J Am Geriatr Soc 63:24852493, 2015.

Key words: elderly; racial disparities; recipient survival; graft survival; kidney transplantation

$\mathrm{O}$ ver the past decade, the number of elderly adults living with end-stage renal disease (ESRD) has increased, with approximately $48 \%$ of people with ESRD now aged 60 and older. ${ }^{1,2}$ Similarly, the percentage of kidney transplant recipients aged 65 and older has increased from $2.4 \%$ to $16 \%$ over the past 2 decades. ${ }^{3-6}$ Kidney transplantation is the preferred treatment for most people with ESRD because it offers longer survival and better quality of life than dialysis for younger and older recipients. $2,7,8$

The rise in the number of older kidney transplant recipients makes it increasingly important to understand the factors affecting graft and recipient survival in the elderly population. Race has been shown to be an important factor affecting graft and recipient survival in kidney transplant recipients. ${ }^{9-11}$ In the general population, black kidney transplant recipients have been shown to have worse graft and recipient survival than white recipients for living and deceased donor transplants, ${ }^{10-14}$ but it is not known whether the racial differences in graft and recipient survival in the general kidney transplant population is also seen in the elderly transplant recipient population. A consensus workshop held on organ transplantation in elderly adults emphasized the need to identify factors underlying disparities in transplant outcomes in elderly adults. ${ }^{15}$ Understanding the role of race and other factors in graft and recipient survival in elderly adults is crucial in reducing disparities and improving outcomes in this population.

The purpose of this study was to evaluate the association between race/ ethnicity and graft and recipient survival after transplantation in elderly (age $\geq 60$ ) kidney transplant recipients. Another goal was to determine potentially modifiable factors that may be associated with 
graft and recipient survival in elderly kidney transplant recipients. It was hypothesized that, consistent with results in the general kidney transplant recipient population, elderly black adults would have worse graft and recipient survival than white recipients and that Asians and Hispanics would have better graft and recipient survival than white recipients.

\section{METHODS}

\section{Data Sources}

Data were obtained from the United Network for Organ Sharing (UNOS), the Social Security Death Index (SSDI), and U.S. Census geographic data for 2000. UNOS is a private organization that the government contracts to manage the transplant waiting list, match donors to recipients, and maintain information about every transplant recipient in the United States, including follow-up data. The SSDI database is a publicly available national database of death records extracted from the U.S. Social Security Administration Death Master File. The Census 2000 data on neighborhood poverty were linked to recipients' residential ZIP codes in the UNOS data using ZIP code tabulation areas.

Data from UNOS were merged with death date information from the SSDI using unique encrypted recipient codes to calculate posttransplantation survival time.

\section{Study Population}

The study population was drawn from the Organ Procurement and Transplantation Network (OPTN) data received from UNOS. The population was restricted to kidney transplant recipients aged 60 and older who were transplanted between July 1996 and October 2010. Participants were followed for outcomes through December 2011. Forty-four thousand thirteen participants were included in the analysis.

\section{Measures}

The main study outcomes were time from kidney transplantation until death (recipient survival time) and time from kidney transplantation until graft failure (graft survival time). Participants who did not experience either of the two study outcomes were censored at the end of follow-up (December 31, 2011). In the analysis of graft survival, recipients who died before graft failure were censored at the time of death (death with a functioning graft was censored rather than treated as graft failure) in an attempt to capture only those with a recorded graft failure event, because death could be a result of various causes, not just a failed graft.

The primary variable of interest was recipient race and ethnicity (self-reported in most cases or as assessed by the transplant center coordinator). Race and ethnicity was classified as black, white, Hispanic, Asian, and other. Recipient demographic factors examined were age at transplant and sex. Primary health insurance at transplantation and neighborhood poverty were proxies for socioeconomic status (SES). Insurance was categorized as private, public (Medicaid, Medicare fee for service, Medicare \& Choice, Depart- ment of Veterans Affairs, other government insurance, and Medicare (further detail not collected)), or other (self, donation, free care, pending). The proportion of individuals residing below the federal poverty level in each five-digit ZIP code was used to estimate the neighborhood poverty level using 2000 U.S Census Bureau data. High neighborhood poverty was defined as areas in which more than $20 \%$ of households were below the federal poverty level. ${ }^{16}$

Additional covariates of interest were recipient clinical characteristics, including primary assigned cause of ESRD categorized into five major groups (diabetes mellitus, hypertension, cystic kidney disease, glomerulonephritis, other) and years on dialysis (defined as number of years on dialysis before transplantation). Donor characteristics assessed were age and type of donor kidney (living or deceased) and, for deceased donor, whether the graft came from a standard criteria donor or extended criteria donor (ECD).

Transplant characteristics were also assessed as covariates, as described below. To account for changes in kidney transplantation practices over time, such as immunosuppression medications and allocation systems, a covariate for year of kidney transplantation was created and then categorized into three time periods (1996-2000, 2001-05, 2006-10). Other transplantation factors evaluated were human leukocyte antigen (HLA) mismatch, cold ischemia time, and reported incidence of any acute rejection. Participants were classified as having experienced acute rejection episodes if they were reported in UNOS to have experienced acute or hyperacute rejection before graft failure or any episode of acute rejection recorded (whether or not they were treated for it) or if they had a kidney biopsy that confirmed acute rejection. Recipient age, donor age, and cold ischemic time were analyzed as continuous variables.

\section{Analysis}

A retrospective cohort analysis of the UNOS database was performed. Kaplan-Meier product-limit curves were generated and stratified according to race and ethnicity, and log-rank statistics for differences between groups were calculated. All predictor variables were evaluated for adherence to the proportional hazards assumption using log-log survival curves, an extended Cox approach using time dependent variables, and a correlation analysis between Schoenfeld residuals and ranked follow-up time.

To evaluate the effect of race and ethnicity on recipient and graft survival, separate multivariable Cox proportional hazard regression models were constructed for graft and recipient survival time as a function of race and ethnicity. Crude and adjusted hazard ratios (HRs) and 95\% confidence intervals (CIs) were computed for race and ethnicity and for all other covariates. Effect estimates for continuous variables, such as recipient age, donor age, years on dialysis, and cold ischemia time, were calculated for a 10-unit change. Variables were considered to be confounders if they were associated with the exposure, race and ethnicity, and the outcomes (graft failure and death). The fully conditional specification method of multiple imputation was used for other missing covariate information $(\mathrm{n}=15,903$ individuals). ${ }^{17} \mathrm{~A}$ complete case analysis was conducted as a sensitivity analysis. The final model was adjusted for recipient age, sex, insurance, ESRD etiology, years on dialysis, 
neighborhood poverty level, donor type, donor age, period of transplantation, cold ischemia time, HLA mismatch, and any acute rejection. All analyses were conducted using SAS version 9.4 (SAS Institute, Inc., Cary, NC), and data were evaluated at the 0.05 significance level.

Approval for this study was obtained from the Emory University institutional review board.

\section{RESULTS}

Table 1 shows the baseline demographic and clinical characteristics of participants stratified according to race and ethnicity. The median age of the 44,013 transplant recipients analyzed was 65 (interquartile range (IQR) 7.0). The population was predominantly male $(62.5 \%)$ and white $(62.4 \%)$. Diabetes mellitus was the most common cause of ESRD $(33.7 \%)$ in all races and ethnicities except blacks, in whom it was hypertension $(40.0 \%)$. Blacks had the highest percentage of acute rejection episodes $(11.8 \%)$, pretransplant dialysis $(93.9 \%)$, and receipt of kidneys from nonECDs $(55.2 \%)$. Asians received the largest percentage of kidneys from ECDs $(31.5 \%)$. Hispanics had the largest $(41.1 \%)$ and whites the smallest $(7.8 \%)$ percentage of people living in the high-poverty areas.

\section{Graft Survival}

\section{Race and Ethnicity}

A total of $14.1 \%$ of recipients experienced a graft failure event over the median of 4.3 years of follow up (IQR 5.2 years), and a greater proportion of blacks $(19.2 \%)$ than of whites $(13.0 \%)$, Hispanics $(11.6 \%)$, and other races $(16.6 \%)$ had graft failure. Table 2 shows the crude and adjusted HRs for graft failure for all covariates examined. Blacks ( $\mathrm{HR}=1.23,95 \% \mathrm{CI}=1.15-1.32)$ were more likely, and Hispanics $(\mathrm{HR}=0.77,95 \% \mathrm{CI}=0.70-0.85)$ and Asians ( $\mathrm{HR}=0.70,95 \% \mathrm{CI}=0.61-0.81)$ were less likely than whites to experience graft failure, after adjusting for covariates (Table 2).

\section{Recipient Demographic Characteristics}

Recipients with public or other insurance were more likely than those with private insurance to experience graft failure after adjusting for covariates ( $\mathrm{HR}=1.09,95 \%$ $\mathrm{CI}=1.03-1.16)$. Recipients with high neighborhood poverty were more likely than those with low neighborhood poverty to experience graft failure $(\mathrm{HR}=1.25,95 \%$ $\mathrm{CI}=1.18-1.33)$ in the crude model, but this association was not significant in the adjusted model $(\mathrm{HR}=1.06$, $95 \% \mathrm{CI}=0.99-1.14)$.

\section{Recipient Clinical Characteristics}

After adjusting for covariates, recipients with cystic kidney disease $(\mathrm{HR}=0.65,95 \% \mathrm{CI}=0.59-0.73)$ and glomerulonephritis $(\mathrm{HR}=0.84,95 \% \mathrm{CI}=0.77-0.91)$ were less likely than those with diabetes mellitus to experience graft failure. Hypertension was not associated with graft failure $(\mathrm{HR}=0.95,95 \% \mathrm{CI}=0.89-1.02)$. A 10-year increase in years on dialysis was associated with a $27 \%$ higher risk of graft failure $(\mathrm{HR}=1.27,95 \% \mathrm{CI}=1.17-1.38)($ Table 2$)$.

\section{Donor Characteristics}

Participants who received a kidney from a non-ECD $(\mathrm{HR}=1.38,95 \% \mathrm{CI}=1.26-1.51)$ and those who received a kidney from an ECD $(\mathrm{HR}=1.78,95 \% \mathrm{CI}=1.61-1.97)$ were more likely than those who received a kidney from a living donor to experience graft failure (Table 2). A 10year increase in donor age was associated with a $16 \%$ greater risk of graft failure $(\mathrm{HR}=1.16,95 \% \mathrm{CI}=1.13$ $1.19)$ in the adjusted models.

\section{Transplant Characteristics}

Participants transplanted between 2001 and 2005 were less likely than trose transplanted between 1996 and 2000 to experience graft failure in the crude model $(\mathrm{HR}=0.89$, $95 \% \mathrm{CI}=0.84-0.95)$, but in the adjusted model, the difference was not statistically significant $(\mathrm{HR}=0.94,95 \%$ $\mathrm{CI}=0.88-1.01)$. Those transplanted between 2006 and 2010 were also less likely to experience graft failure than those transplanted between 1996 and 2000 in crude $(\mathrm{HR}=0.74, \quad 95 \% \quad \mathrm{CI}=0.69-0.80) \quad$ and adjusted $(\mathrm{HR}=0.74,95 \% \mathrm{CI}=0.69-0.80)$ models.

Having two or more HLA mismatches was significantly associated with greater likelihood of graft failure than having no HLA mismatches.

Recipients who experienced any acute rejection episode were significantly more likely to have graft failure than those without an acute rejection episode in crude $(\mathrm{HR}=2.53 ; \quad 95 \% \quad \mathrm{CI}=2.38-2.69) \quad$ and adjusted $(\mathrm{HR}=2.25,95 \% \mathrm{CI}=2.11-2.40)$ models.

Figure 1 shows Kaplan-Meier estimates for unadjusted graft survival comparing elderly black, Hispanic, and Asian with white renal transplant recipients from July 1996 to October 2010, with follow-up until December 2011 (median follow-up 4.3 years).

\section{Participant Survival}

\section{Race and Ethnicity}

A total of $37.4 \%$ of participants died over the median 4.6 years of follow-up (IQR 2.5-7.3 years), and a greater proportion of whites $(38.8 \%)$ than of blacks $(37.7 \%)$, Hispanics $(32.3 \%)$, and other races $(27.6 \%)$ died. The median survival time was 9.1 years for all participants, 8.8 years for whites it was, 8.9 years for African Americans, 11.3 years for Asians, 10.3 years for Hispanics, and 8.7 years for persons of other races and ethnicities. Table 2 shows crude and adjusted HRs for recipient death according to race and other covariates examined. Blacks $(\mathrm{HR}=0.84,95 \% \mathrm{CI}=0.80-0.88)$, Hispanics $(\mathrm{HR}=0.68$, $95 \% \mathrm{CI}=0.64-0.72)$, and Asians $(\mathrm{HR}=0.62,95 \%$ $\mathrm{CI}=0.57-0.68)$ all had a lower likelihood of death than whites.

\section{Recipient Demographics}

Men had a $15 \%$ greater likelihood of death than women $(\mathrm{HR}=1.15,95 \% \mathrm{CI}=1.11-1.19)$. Recipients with public insurance had a $15 \%$ greater likelihood of death than those with private insurance $(\mathrm{HR}=1.15, \quad 95 \%$ $\mathrm{CI}=1.11-1.19)$ in the adjusted model. A 10 -year incre- 
Table 1. Baseline Characteristics of Elderly ( $\geq 60)$ Renal Transplant Recipients from July 1996 to October 2010 According to Race and Ethnicity

\begin{tabular}{|c|c|c|c|c|c|c|}
\hline Characteristic & $\begin{array}{c}\text { Overall, } \\
N=44,013\end{array}$ & $\begin{array}{c}\text { White, } n=27,481 \\
(62.4 \%)\end{array}$ & $\begin{array}{c}\text { Black, } n=8,903 \\
(20.2 \%)\end{array}$ & $\begin{array}{c}\text { Hispanic, } \\
\mathrm{n}=4,669(10.6 \%)\end{array}$ & $\begin{array}{c}\text { Asian, } \\
\mathrm{n}=2,095(4.8 \%)\end{array}$ & $\begin{array}{c}\text { Other, } n=865 \\
(2.0 \%)\end{array}$ \\
\hline \multicolumn{7}{|l|}{ Recipient demographic } \\
\hline Male, $n(\%)$ & $27,512(62.5)$ & $17,669(64.3)$ & $5,128(57.6)$ & 2,957 (63.3) & $1,238(59.1)$ & $520(60.1)$ \\
\hline \multicolumn{7}{|l|}{ Insurance type, n (\%) } \\
\hline Private & $13,585(31.1)$ & 9,407 (34.3) & $2,183(24.5)$ & $1,097(23.5)$ & $1,664(31.7)$ & $234(27.1)$ \\
\hline$>20 \%$ & $7,653(17.4)$ & $2,008(7.6)$ & 3,267 (37.8) & $1,835(41.1)$ & $245(12.1)$ & $298(35.6)$ \\
\hline$\leq 20 \%$ & $34,858(79.2)$ & $24,536(92.4)$ & $5,370(62.2)$ & $2,632(58.9)$ & $1,782(87.9)$ & $538(64.3)$ \\
\hline \multicolumn{7}{|l|}{ Employed, $\mathrm{n}(\%)^{\mathrm{a}}$} \\
\hline No & $19,393(81.1)$ & $11,341(77.9)$ & $4,212(86.2)$ & $2,417(88.1)$ & $1,053(82.0)$ & $370(84.7)$ \\
\hline Yes & $4,513(18.9)$ & $3,211(22.1)$ & $676(13.8)$ & 328 (11.9) & $231(18.0)$ & $67(15.3)$ \\
\hline \multicolumn{7}{|l|}{ Recipient clinical } \\
\hline Glomerulonephritis & $6,128(15.3)$ & 4,536 (18.6) & $703(8.3)$ & 469 (10.7) & $321(16.0)$ & 99 (12.2) \\
\hline Other & $6,774(16.9)$ & $5,011(20.6)$ & $862(10.2)$ & $519(11.9)$ & $315(15.7)$ & $67(8.3)$ \\
\hline \multicolumn{7}{|c|}{ Pretransplantation dialysis, $\mathrm{n}(\%)^{\mathrm{a}}$} \\
\hline No & $6,122(13.9)$ & $5,045(18.4)$ & $545(6.1)$ & $294(6.3)$ & $178(8.5)$ & $60(7.0)$ \\
\hline Yes & $37,848(86.1)$ & $22,408(81.6)$ & $8,355(93.9)$ & 4,366 (93.7) & $1,916(91.5)$ & $803(93)$ \\
\hline $\begin{array}{l}\text { Years on dialysis, } \\
\text { median (IQR) }\end{array}$ & $2.47(2.81)$ & $2.02(2.29)$ & $3.44(3.27)$ & $3.15(3.30)$ & $3.09(3.11)$ & $3.35(3.09)$ \\
\hline \multicolumn{7}{|l|}{ Donor } \\
\hline \multicolumn{7}{|l|}{ Type of donor, $n(\%)^{a}$} \\
\hline Living & $13,212(30.0)$ & $9,761(35.5)$ & $1,588(17.8)$ & $1,234(26.4)$ & $422(20.1)$ & $207(23.9)$ \\
\hline Deceased non-ECD & $21,387(48.6)$ & $12,646(46.0)$ & $4,914(55.2)$ & $2,375(50.9)$ & $1,014(48.4)$ & $438(50.6)$ \\
\hline \multicolumn{7}{|c|}{ Number of HLA mismatches, $\mathrm{n}(\%)^{\mathrm{a}}$} \\
\hline 0 & $3,897(8.9)$ & $3,046(11.1)$ & $294(3.3)$ & $419(9.0)$ & $80(3.8)$ & $58(6.7)$ \\
\hline 1 & $1,901(4.3)$ & $1,446(5.3)$ & $222(2.5)$ & $157(3.4)$ & $46(2.2)$ & $30(3.5)$ \\
\hline 2 & $4,605(10.5)$ & $3,300(12.1)$ & $609(6.9)$ & $470(10.1)$ & $142(6.8)$ & $84(9.7)$ \\
\hline 3 & 8,535 (19.5) & $5,834(21.3)$ & $1,411(15.9)$ & $880(18.9)$ & $254(12.2)$ & $156(18.1)$ \\
\hline 4 & $8,948(20.4)$ & $5,342(19.5)$ & $2,003(22.6)$ & $950(20.4)$ & $479(23.0)$ & $174(20.1)$ \\
\hline 5 & $10,402(23.7)$ & $5,557(20.3)$ & $2,745(30.9)$ & $1,184(25.5)$ & 691 (33.2) & $225(26.0)$ \\
\hline 6 & $5,536(12.6)$ & $2,827(10.3)$ & $1,590(17.9)$ & $591(12.7)$ & $391(18.8)$ & $137(15.9)$ \\
\hline $\begin{array}{l}\text { Cold ischemia time, } \\
\text { median (IQR) }\end{array}$ & $15(18.0)$ & $14(19.0)$ & $16.3(13.0)$ & $15.5(15.0)$ & $15(14.3)$ & $14(13.5)$ \\
\hline \multicolumn{7}{|l|}{ Acute rejection, $\mathrm{n}(\%)$} \\
\hline No & 39,577 (89.9) & 24,698 (89.9) & $7,852(88.2)$ & 4,289 (91.9) & $1,956(93.4)$ & $782(90.4)$ \\
\hline Yes & 4,436 (10.1) & $2,783(10.1)$ & 1,051 (11.8) & $380(8.1)$ & $139(6.6)$ & $83(9.6)$ \\
\hline
\end{tabular}

${ }^{a}$ Missing data: insurance type, $0.1 \%$; neighborhood poverty, 3.4\%; employment, $46.0 \%$; end-stage renal disease (ESRD) etiology, $9.1 \%$; pretransplantaiton dialysis, $0.01 \%$; years on dialysis, $20.2 \%$; donor type, $0.004 \%$; human leukocyte antigen (HLA) mismatch, $0.4 \%$; cold ischemia time, $7.9 \%$.

$\mathrm{IQR}=$ interquartile range; $\mathrm{ECD}=$ extended criteria donor.

ment in recipient age was associated with a $55 \%$ $(\mathrm{HR}=1.55,95 \% \mathrm{CI}=1.50-1.60)$ and $47 \% \quad(\mathrm{HR}=1.47$, $95 \% \mathrm{CI}=1.42-1.52$ ) higher rate of death in the crude and adjusted models, respectively. Neighborhood poverty was not associated recipient survival (HR1.01, 95\% $\mathrm{CI}=0.97-1.06)$.

\section{Recipient Clinical Characteristics}

After adjusting for covariates, recipients with hypertension as the primary etiology of ESRD $(\mathrm{HR}=0.72,95 \%$ $\mathrm{CI}=0.69-0.75)$, cystic kidney disease $(\mathrm{HR}=0.43,95 \%$ $\mathrm{CI}=0.40-0.46), \quad$ and glomerulonephritis $\quad(\mathrm{HR}=0.54$, 
Table 2. Unadjusted and Adjusted Hazard of Death and Graft Failure in Elderly ( $\geq 60)$ Renal Transplant Recipients from July 1996 to October 2010 According to Race and Ethnicity

\begin{tabular}{ccccc}
\multicolumn{2}{c}{ Death } & & \multicolumn{2}{c}{ Graft Failure } \\
\cline { 1 - 1 } Crude & Adjusted $^{\mathrm{a}}$ & & Crude & Adjusted $^{\mathrm{a}}$ \\
\hline
\end{tabular}

Characteristic

Hazard Ratio (95\% Confidence Interval)

\begin{tabular}{|c|c|c|c|c|}
\hline \multicolumn{5}{|l|}{ Recipient demographic } \\
\hline \multicolumn{5}{|l|}{ Race and ethnicity (reference white) } \\
\hline African American & $1.02(0.98-1.07)$ & $0.84(0.80-0.88)^{\mathrm{b}}$ & $1.60(1.51-1.69)^{\mathrm{b}}$ & $1.23(1.15-1.32)^{\mathrm{b}}$ \\
\hline Hispanic & $0.81(0.76-0.86)^{b}$ & $0.68(0.64-0.72)^{b}$ & $0.89(0.81-0.98)^{\mathrm{b}}$ & $0.77(0.70-0.85)^{\mathrm{b}}$ \\
\hline Asian & $0.71(0.65-0.78)^{\mathrm{b}}$ & $0.62(0.57-0.68)^{b}$ & $0.85(0.74-0.97)^{b}$ & $0.70(0.61-0.81)^{\mathrm{b}}$ \\
\hline Other & $1.02(0.92-1.14)$ & $0.82(0.74-0.92)^{b}$ & $1.27(1.08-1.50)^{\mathrm{b}}$ & $1.05(0.88-1.25)$ \\
\hline $\mathrm{Age}^{\mathrm{C}}$ & $1.55(1.50-1.60)^{b}$ & $1.47(1.42-1.52)$ & $1.02(0.96-1.08)$ & $0.94(0.89-1.00)$ \\
\hline Male & $1.23(1.19-1.27)^{b}$ & $1.15(1.11-1.19)^{b}$ & $1.07(1.02-1.13)^{\mathrm{b}}$ & $1.04(0.98-1.09)$ \\
\hline Insurance type public and other (reference private) & $1.39(1.34-1.44)^{b}$ & $1.15(1.11-1.19)^{b}$ & $1.26(1.19-1.33)^{b}$ & $1.09(1.03-1.16)^{b}$ \\
\hline Neighborhood poverty $>20 \%$ (high poverty) & $1.03(0.99-1.07)$ & $1.01(0.97-1.06)$ & $1.25(1.18-1.33)^{b}$ & $1.06(0.99-1.14)$ \\
\hline \multicolumn{5}{|l|}{ Clinical } \\
\hline \multicolumn{5}{|l|}{ ESRD etiology (reference diabetes mellitus) } \\
\hline Hypertension & $0.79(0.76-0.82)^{b}$ & $0.72(0.69-0.75)^{b}$ & $1.05(0.98-1.12)$ & $0.95(0.89-1.02)$ \\
\hline Cystic kidney disease & $0.46(0.43-0.50)$ & $0.43(0.40-0.46)$ & $0.66(0.59-0.73)$ & $0.65(0.59-0.73)$ \\
\hline Glomerulonephritis & $0.59(0.56-0.62)^{b}$ & $0.54(0.51-0.57)^{b}$ & $0.82(0.75-0.89)^{b}$ & $0.84(0.77-0.91)^{b}$ \\
\hline Other & $0.76(0.72-0.80)^{b}$ & $0.67(0.64-0.70)^{b}$ & $0.95(0.88-1.03)$ & $0.93(0.87-1.01)$ \\
\hline Years on dialysis ${ }^{\mathrm{C}}$ & $1.39(1.33-1.46)^{b}$ & $1.39(1.33-1.45)^{b}$ & $1.49(1.39-1.59)^{b}$ & $1.27(1.17-1.38)^{b}$ \\
\hline \multicolumn{5}{|l|}{ Donor } \\
\hline \multicolumn{5}{|l|}{ Type (reference living) } \\
\hline Deceased non-ECD & $1.43(1.38-1.49)^{\mathrm{b}}$ & $1.33(1.25-1.41)^{b}$ & $1.54(1.44-1.65)^{\mathrm{b}}$ & $1.38(1.26-1.51)^{b}$ \\
\hline Deceased ECD & $1.88(1.80-1.97)^{\mathrm{b}}$ & $1.42(1.33-1.52)^{b}$ & $3.06(2.85-3.28)^{\mathrm{b}}$ & $1.78(1.61-1.97)^{\mathrm{b}}$ \\
\hline $\mathrm{Age}^{\mathrm{C}}$ & $1.09(1.08-1.10)^{b}$ & $1.06(1.05-1.08)^{b}$ & $1.25(1.23-1.27)^{b}$ & $1.16(1.13-1.19)^{b}$ \\
\hline \multicolumn{5}{|l|}{ Transplant } \\
\hline \multicolumn{5}{|l|}{ Period of transplant (reference 1996-2000) } \\
\hline 2001-2005 & $0.88(0.85-0.92)^{b}$ & $0.86(0.83-0.90)^{b}$ & $0.89(0.84-0.95)^{b}$ & $0.94(0.88-1.01)$ \\
\hline $2006-2010$ & $0.73(0.69-0.76)^{b}$ & $0.66(0.63-0.70)^{b}$ & $0.74(0.69-0.80)^{b}$ & $0.74(0.69-0.80)^{b}$ \\
\hline \multicolumn{5}{|l|}{ Number of HLA mismatches (reference 0 ) } \\
\hline 1 & $1.05(0.97-1.15)$ & $1.10(1.01-1.20)$ & $0.99(0.84-1.17)$ & $1.04(0.87-1.23)$ \\
\hline 2 & $0.93(0.86-1.00)^{b}$ & $1.07(0.99-1.15)$ & $1.06(0.93-1.20)$ & $1.16(1.01-1.33)$ \\
\hline 3 & $1.00(0.94-1.07)$ & $1.10(1.03-1.17)^{\mathrm{b}}$ & $1.22(1.09-1.37)$ & $1.25(1.11-1.40)^{b}$ \\
\hline 4 & $1.16(1.09-1.23)^{b}$ & $1.12(1.05-1.20)^{\mathrm{b}}$ & $1.68(1.50-1.88)^{b}$ & $1.35(1.20-1.51)^{\mathrm{b}}$ \\
\hline 5 & $1.19(1.12-1.27)^{b}$ & $1.15(1.08-1.22)^{b}$ & $1.76(1.58-1.96)^{b}$ & $1.39(1.24-1.56)^{b}$ \\
\hline 6 & $1.22(1.14-1.31)^{\mathrm{b}}$ & $1.18(1.10-1.26)^{b}$ & $1.99(1.77-2.23)^{\mathrm{b}}$ & $1.52(1.34-1.71)^{b}$ \\
\hline Cold ischemia time $^{d}$ & $1.14(1.12-1.15)^{b}$ & $1.03(1.01-1.05)^{b}$ & $1.21(1.19-1.24)^{b}$ & $1.08(1.05-1.11)^{b}$ \\
\hline Acute rejection & $1.35(1.29-1.41)^{b}$ & $1.26(1.20-1.32)^{b}$ & $2.53(2.38-2.69)^{b}$ & $2.25(2.11-2.40)^{\mathrm{b}}$ \\
\hline
\end{tabular}

${ }^{a}$ Adjusted for race and ethnicity, any acute rejection, end-stage renal disease (ESRD) etiology, sex, human leukocyte antigen (HLA) mismatch, pretransplantaiton dialysis, type of donor, recipient age, donor age, cold ischemia time, insurance, neighborhood poverty, and period of transplantation.

${ }^{\mathrm{b}} \mathrm{P}<.05$.

${ }^{\mathrm{c}}$ Effect estimate calculated for a 10 -year change in age.

${ }^{\mathrm{d} E f f e c t}$ estimate calculated for a 10 -year change in time on dialysis.

${ }^{\mathrm{e}}$ Effect estimate calculated for a 10-hour change in time ischemia time.

$\mathrm{ECD}=$ extended criteria donor.

$95 \% \mathrm{CI}=0.51-0.57)$ had a lower likelihood of death than those with diabetes mellitus. A 10 -year increase in years on dialysis was associated with a $39 \%$ greater likelihood of death $(\mathrm{HR}=1.39,95 \% \mathrm{CI}=1.33-1.45)$. Having three or more HLA mismatches was significantly associated with greater likelihood of death than having no HLA mismatches.

\section{Donor Characteristics}

Persons who received kidneys from non-ECDs $(\mathrm{HR}=1.33$, $95 \% \mathrm{CI}=1.25-1.41)$ and, more so, those who received kidneys from ECDs $(\mathrm{HR}=1.42,95 \% \mathrm{CI}=1.33-1.52)$ had a greater risk of death than those who received living- donor kidneys (Table 2). A 10-year increase in donor age was associated with a $6 \%$ greater likelihood of death $(\mathrm{HR}=1.06,95 \% \mathrm{CI}=1.05-1.08)$.

\section{Transplant Characteristics}

Recipients transplanted from 2001 to 2005 ( $\mathrm{HR}=0.86$, $95 \% \mathrm{CI}=0.83-0.90)$ and 2006 to $2010 \quad(\mathrm{HR}=0.66$, $95 \%$ CI $=0.63-0.70)$ had a lower likelihood of death than transplanted from 1996 to 2000. Recipients who experienced an acute rejection episode had a greater likelihood of death than those who did not in the crude $(\mathrm{HR}=1.35$, $95 \% \mathrm{CI}=1.29-1.41)$ and adjusted $(\mathrm{HR}=1.26,95 \%$ $\mathrm{CI}=1.20-1.32)$ model. Figure $2 \mathrm{a}-\mathrm{c}$ shows Kaplan-Meir 

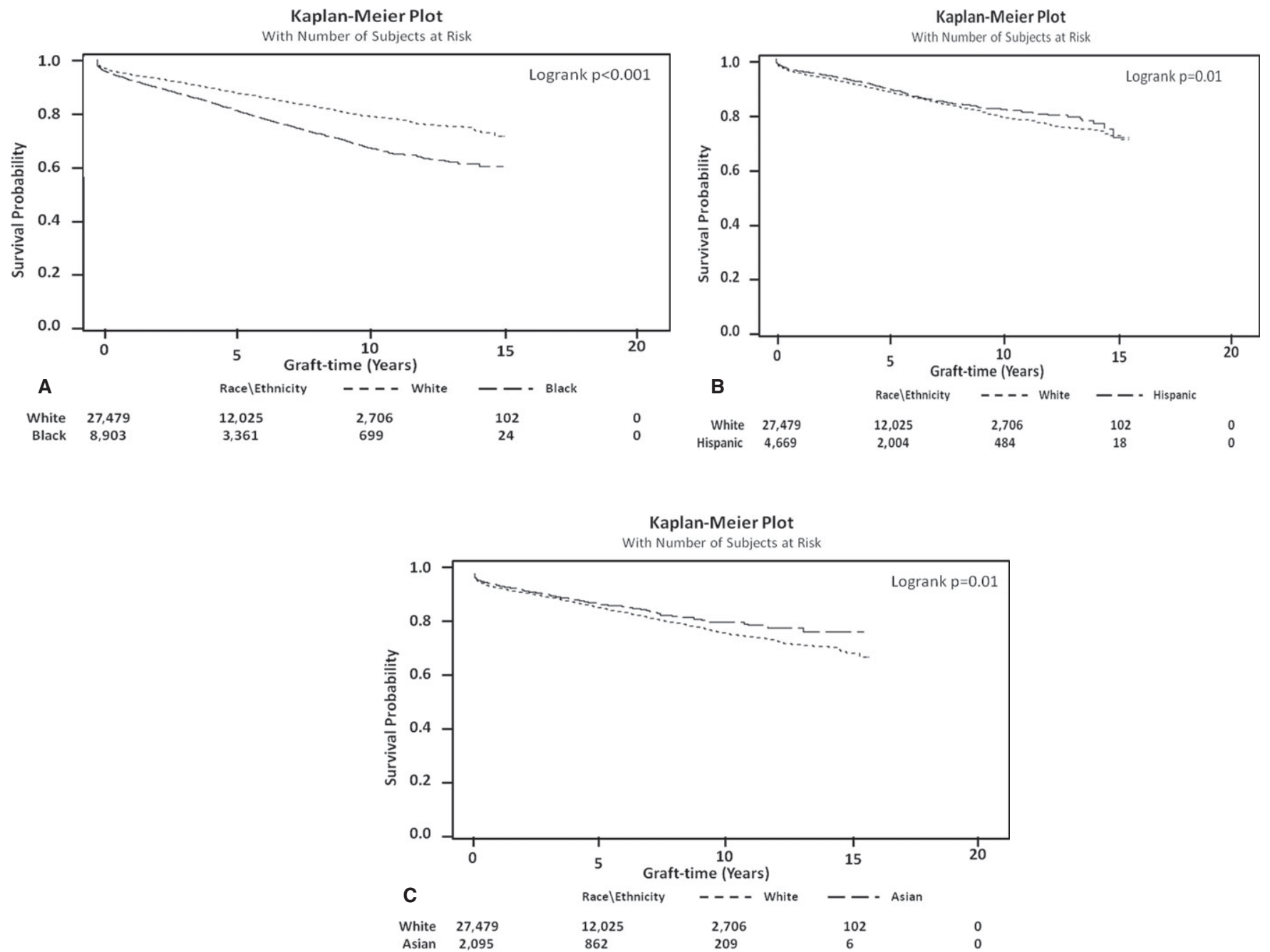

Figure 1. Kaplan-Meier estimates showing unadjusted graft survival in elderly renal transplant recipients from July 1996 to October 2010, with recipient follow-up until December 2011.

estimates for unadjusted recipient survival in black, Hispanic, and Asian recipients compared with white recipients over a median follow-up of 4.6 years.

Using complete-case analysis, multivariable results for effect of race and ethnicity on recipient or graft survival did not differ significantly from the main analysis; similarly, stratifying according to age $(60-70$ vs $>70)$ did not yield significant differences in trends for recipient and graft survival (S1 and S2).

\section{DISCUSSION}

This study sought to evaluate the effect of race and ethnicity on graft and recipient survival in elderly $(\geq 60)$ kidney transplant recipients and to determine other factors that may be associated with graft and recipient survival. A consensus study on organ transplantation in elderly adults found that there was a lack of data addressing age in minority and nonminority transplant recipients and stressed the need for studies identifying biological, behavioral, and social mechanisms contributing to long-term posttransplantation outcomes in elderly adults. ${ }^{15}$
The major findings of the current study were that blacks were more likely than whites to experience graft failure $(\mathrm{HR}=1.23,95 \% \mathrm{CI}=1.15-1.32)$, whereas Hispanics $(\mathrm{HR}=0.77,95 \% \mathrm{CI}=0.70-0.85)$ and Asians $(\mathrm{HR}=0.70,95 \% \mathrm{CI}=0.61-0.81) \quad$ were less likely to experience graft failure. Second, blacks $(\mathrm{HR}=0.84,95 \%$ $\mathrm{CI}=0.80-0.88)$, Hispanics $(\mathrm{HR}=0.68,95 \% \mathrm{CI}=0.64$ $0.72)$, and Asians ( $\mathrm{HR}=0.62,95 \% \mathrm{CI}=0.57-0.68)$ were less likely than whites to die after renal transplantation. These results indicate that race and ethnicity may be an independent risk factor for graft failure in elderly adults but does not necessarily affect recipient survival in the same manner. These findings support previous studies in the general kidney transplant population showing superior recipient and graft survival in Hispanics ${ }^{18-20}$ and Asians ${ }^{21}$ and worse graft survival in blacks than whites. ${ }^{9,11,22}$ Although recipient survival has been shown to be equivalent ${ }^{11,23}$ or worse ${ }^{10,24,25}$ in blacks than nonblacks, the current study found greater recipient survival in blacks aged 60 and older than in whites.

Previous studies have shown that the half-life of renal allografts after transplantation appears to be $30 \%$ to $40 \%$ 

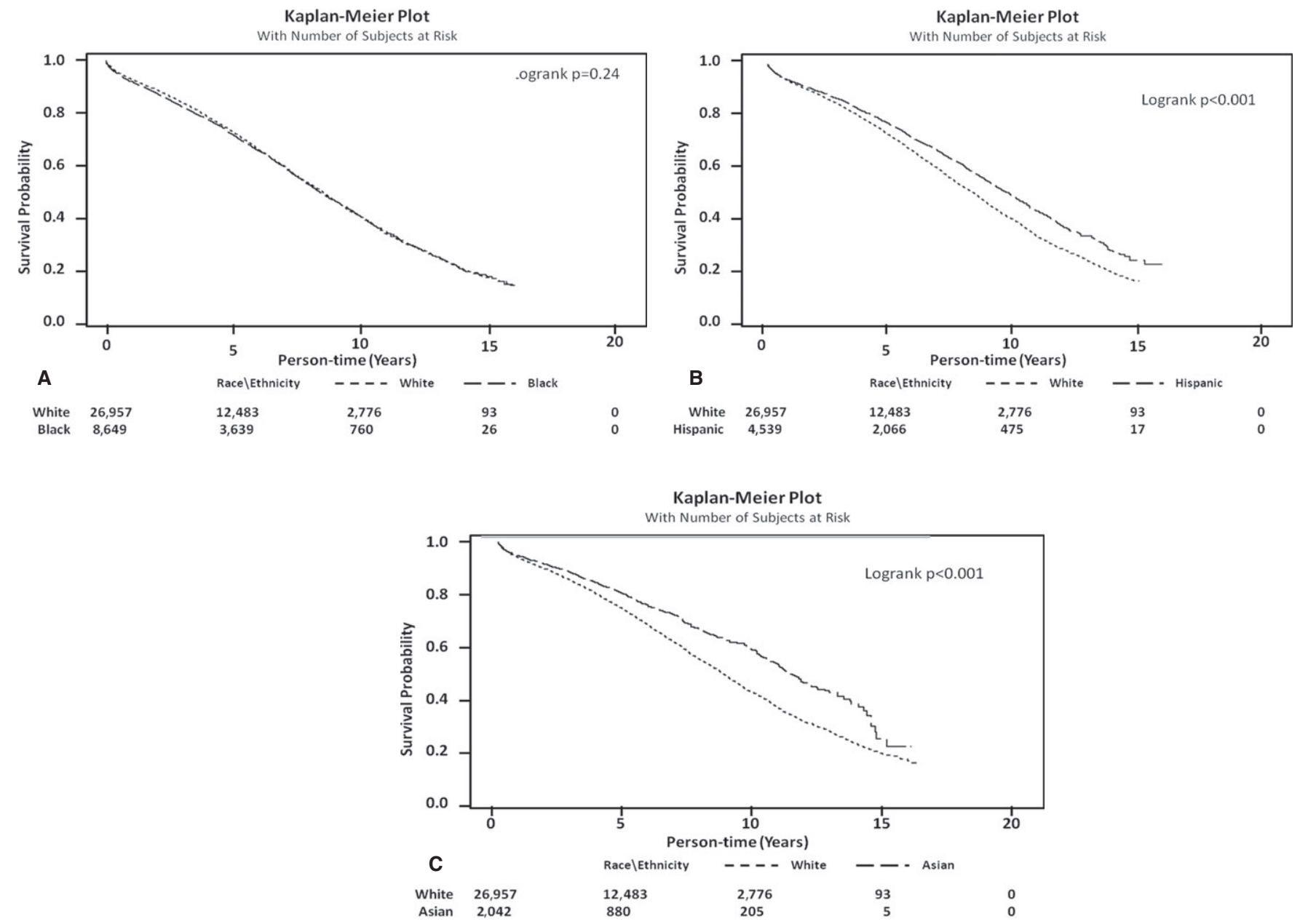

Figure 2. Kaplan-Meier estimates showing unadjusted survival of elderly renal transplant recipients from July 1996 to October 2010, with recipient follow-up until December 2011.

shorter in blacks than whites. ${ }^{10,26}$ In pediatric transplant recipients, blacks had the lowest graft survival rates before the 3-year mark, when Medicare eligibility ends. ${ }^{27}$ It could be that biological factors affect graft loss more than socioeconomic factors in elderly black adults because they remain eligible for Medicare more than 3 years after transplantation and are better able to afford immunosuppressive medication than those who are younger than 65 , who lose Medicare eligibility after 3 years.

The current results on graft survival support the "Hispanic paradox," which has shown that, although Hispanics have low SES similar to that of blacks, their mortality is equal to or lower than that of non-Hispanic whites in the United States. ${ }^{18,28}$ This paradox is described in the transplantation population and is hypothesized to be related to age, occurring predominantly in middle-aged and older Hispanics. ${ }^{18,29,30}$ Previous studies have showed that socioeconomic characteristics of individual neighborhoods may have a vital but underappreciated effect on health outcomes, even more-so than individual SES (e.g., income and employment status)..$^{31-34}$ This study showed that insurance but not neighborhood poverty was associated with graft and recipient survival, however, SES is complex and multifactorial and may not be fully represented by a single variable. ${ }^{34,35}$ Therefore, an observed racial or ethnic disparity may not be completely independent of SES; ${ }^{36}$ neither can socioeconomic differences completely account for these disparities. ${ }^{37-39}$ In addition to psychosocial factors and access to care, other biological factors such as genetic, immune, and pharmacokinetic factors may contribute to poorer graft outcomes in lacks.

The findings of the current study differ from those of previous studies, which showed no difference in 5-year recipient survival rates between black and white recipients. ${ }^{11}$ One study found no significant difference in 1 - and 5 -year recipient survival rates between black and nonblack recipients of kidneys from living and deceased donors. ${ }^{23}$ The current study showed that elderly recipients receiving kidneys from ECDs have the greater likelihood of death. ${ }^{40,41}$ Increased immunosuppression use and a higher rate of acute rejection, which also contributes to heightened immunosuppression and thus more deaths, may explain this. ${ }^{40}$

Blacks, Hispanics, and Asians were less likely to die after renal transplantation than whites, but blacks had worse graft survival than whites. The reason for this paradox is unclear, but a possible explanation is that blacks and Hispanics who are selected for transplantation may have a lower cardiovascular disease burden and less-severe comorbidities than whites, creating a survival bias, with 
the healthiest candidates being presented for transplantation. It has also been suggested that older, sicker Hispanics return to their country of origin, resulting in fewer reported deaths. ${ }^{42,43}$ Alternatively, heightened immunological response to the graft may cause a higher rate of graft loss in blacks ${ }^{44-47}$ but not necessarily lead to greater risk of death. A survival paradox also exists in Hispanics and older non-Hispanic blacks on dialysis. A previous study found that Hispanic individuals undergoing dialysis had lower mortality risk than non-Hispanic whites in all age groups and that blacks aged 30 and older had a lower mortality risk than whites. ${ }^{48}$ Another study found that Hispanics on dialysis had lower mortality than whites in all age groups, but in blacks, the lower mortality was evident only in those aged 40 and older. ${ }^{42}$

Hypertension was the leading cause of ESRD in black recipients, supporting previous studies showing that blacks are more likely to be labelled as having hypertensive renal disease even when other causes of ESRD exist. ${ }^{49,50}$

Its retrospective nature and the inability to adjust for unknown or unmeasured confounders limited the current study. The acute rejection variable may not have captured everyone with an acute rejection. Also, according to UNOS, as of November 2011, the percentage of deaths accessible in the Social Security Death Master File decreased significantly because of data release problems with the Social Security Administration. As such, persons who died during the last month of follow-up in the current study (November 2011 to December 2011) might not have been accurately captured. In addition, because the outcome of interest was graft failure, recipients who died with a functioning graft were censored and not counted as failed grafts, even though it is possible that incipient graft failure was the reason for death. A unique strength of the study is the fact that all persons in the UNOS database who received a transplant during the specified period were examined, and thus, the results are representative of the elderly U.S. transplant population.

\section{CONCLUSION}

Elderly black, Hispanic, and Asian transplant recipients had higher survival rates than whites, but only blacks had worse graft survival than whites. Further studies may be needed to identify specific immunological and nonimmunological factors such as currently unmeasured socioeconomic effects that may affect graft loss. Identifying potentially novel factors that may explain these differences is essential to improve graft survival in elderly adults and ensure equity in outcomes across all racial and ethnic groups.

\section{ACKNOWLEDGMENTS}

Special thanks to Dr. Laura Plantinga for proofreading the manuscript.

Funded by National Heart, Lung, Blood and Sleep Institute, National Institutes of Health (R25 HL105401), Atlanta Clinical and Translational Science Institute, and National Institute of Minority Health and Health Disparities (R24MD008077).

Titilayo O. Ilori receives educational support from the ACTSI. This study was supported in part from divisional funds of the Department of Nephrology, Emory University, Atlanta, Georgia. This publication was also supported in part by the National Heart, Lung, Blood and Sleep Institute, National Institutes of Health (NIH), through Grant R25 HL105401. REP is supported in part by the National Institute of Minority Health and Health Disparities (R24MD008077). This work was supported in part by Health Resources and Services Administration Contract 234-2005-370011C. The content is solely the responsibility of the authors and does not necessarily represent the official views of the NIH or the views or policies of the Department of Health and Human Services, nor does mention of trade names, commercial products, or organizations imply endorsement by the U.S. government.

Conflict of Interest: The authors declare no competing interests.

Author Contributions: Titilayo O. Ilori was responsible for writing the manuscript and had full access to all of the data in the study and takes primary responsibility for the integrity of the data, accuracy of the data analysis, and final content of the manuscript. Ilori, McClellan, Patzer: study design. Adedinsewo, Enofe, Ilori: data analysis. Adedinsewo, Odewole, Enofe, Ojo, McClellan, Patzer: writing the manuscript. All authors read and approved the final manuscript for submission.

Sponsor's Role: None.

\section{REFERENCES}

1. U.S. Renal Data System 2012. Annual Data Report: Atlas of Chronic Kidney Disease and End-Stage Renal Disease in the United States. Bethesda, MD: National Institutes of Health, 2012.

2. Abecassis M, Bartlett ST, Collins AJ et al. Kidney transplantation as primary therapy for end-stage renal disease: A National Kidney Foundation/ Kidney Disease Outcomes Quality Initiative (NKF/KDOQI (TM)) Conference. Clin J Am Soc Nephrol 2008;3:471-480.

3. Hartmann EL, Wu C. The evolving challenge of evaluating older renal transplant candidates. Adv Chronic Kidney Dis 2010;17:358-367.

4. Jager KJ, van Dijk PC, Dekker FW et al. The epidemic of aging in renal replacement therapy: An update on elderly patients and their outcomes. Clin Nephrol 2003;60:352-360.

5. Danovitch GM, Cohen DJ, Weir MR et al. Current status of kidney and pancreas transplantation in the United States, 1994-2003. Am J Transplant 2005;5(4 Pt 2):904-915.

6. Wolfe RA, Merion RM, Roys EC et al. Trends in organ donation and transplantation in the United States, 1998-2007. Am J Transplant 2009;9 (4 Pt 2):869-878.

7. Oniscu GC, Brown H, Forsythe JL. How great is the survival advantage of transplantation over dialysis in elderly patients? Nephrol Dial Transplant 2004;19:945-951.

8. Mendonca HM, Dos Reis MA, de Castro de Cintra Sesso R et al. Renal transplantation outcomes: A comparative analysis between elderly and younger recipients. Clin Transplant 2007;21:755-760.

9. Isaacs RB, Nock SL, Spencer CE et al. Racial disparities in renal transplant outcomes. Am J Kidney Dis 1999;34:706-712.

10. Eckhoff DE, Young CJ, Gaston RS et al. Racial disparities in renal allograft survival: A public health issue? J Am Coll Surg 2007;204:894-902; discussion 902-903.

11. Moore DE, Feurer ID, Rodgers $\mathrm{S} \mathrm{Jr}$ et al. Is there racial disparity in outcomes after solid organ transplantation? Am J Surg 2004;188:571574.

12. Patzer RE, Pearson TC. Racial disparities in kidney graft survival: Does donor quality explain the difference? Am J Transplant 2012;12:1670 1671.

13. Chakkera HA, O'Hare AM, Johansen KL et al. Influence of race on kidney transplant outcomes within and outside the Department of Veterans Affairs. J Am Soc Nephrol 2005;16:269-277.

14. Fan PY, Ashby VB, Fuller DS et al. Access and outcomes among minority transplant patients, 1999-2008, with a focus on determinants of kidney graft survival. Am J Transplant 2010;10:1090-1107. 
15. Abecassis M, Bridges ND, Clancy CJ et al. Solid-organ transplantation in older adults: Current status and future research. Am J Transplant 2012;12:2608-2622.

16. Patzer RE, Amaral S, Wasse $\mathrm{H}$ et al. Neighborhood poverty and racial disparities in kidney transplant waitlisting. J Am Soc Nephrol 2009;20:13331340 .

17. van Buuren S. Multiple imputation of discrete and continuous data by fully conditional specification. Stat Methods Med Res 2007;16:219-242.

18. Gordon EJ, Caicedo JC. Ethnic advantages in kidney transplant outcomes: The Hispanic Paradox at work? Nephrol Dial Transplant 2009;24:11031109.

19. Gjertson DW. Determinants of long-term survival of adult kidney transplants: A 1999 UNOS update. Clin Transpl 1999:341-352.

20. Gjertson DW. A multi-factor analysis of kidney graft outcomes at one and five years posttransplantation: 1996 UNOS Update. Clin Transpl 1996:343-360

21. Katznelson S, Gjertson DW, Cecka JM. The effect of race and ethnicity on kidney allograft outcome. Clin Transpl 1995:379-394.

22. Butkus DE, Meydrech EF, Raju SS. Racial differences in the survival of cadaveric renal allografts. Overriding effects of HLA matching and socioeconomic factors. N Engl J Med 1992;327:840-845.

23. Foster CE, Philosophe B, Schweitzer EJ et al. A decade of experience with renal transplantation in African-Americans. Ann Surg 2002;236:794-804; discussion 804-805.

24. Wolfe RA, Ashby VB, Milford EL et al. Comparison of mortality in all patients on dialysis, patients on dialysis awaiting transplantation, and recipients of a first cadaveric transplant. N Engl J Med 1999;341:1725-1730.

25. Ojo AO, Hanson JA, Wolfe RA et al. Long-term survival in renal transplant recipients with graft function. Kidney Int 2000;57:307-313.

26. Young CJ, Gaston RS. Renal transplantation in black Americans. N Engl J Med 2000;343:1545-1552.

27. Patzer RE, Mohan S, Kutner $\mathrm{N}$ et al. Racial and ethnic disparities in pediatric renal allograft survival in the United States. Kidney Int 2015;87:584-592.

28. Markides KS, Coreil J. The health of Hispanics in the southwestern United States: An epidemiologic paradox. Public Health Rep 1986;101:253-265.

29. Franzini L, Ribble JC, Keddie AM. Understanding the Hispanic paradox. Ethn Dis 2001;11:496-518.

30. Markides KS, Eschbach K. Aging, migration, and mortality: Current status of research on the Hispanic paradox. J Gerontol B Psychol Sci Soc Sci 2005;60B(Spec No 2):68-75.

31. Massey DS. American apartheid - segregation and the making of the underclass. Am J Sociol 1990;96:329-357.

32. Sampson RJ, Sharkey P. Neighborhood selection and the social reproduction of concentrated racial inequality. Demography 2008;45:1-29.

33. Wilson WJ. The Truly Disadvantaged: The Inner City, the Underclass, and Public Policy. Chicago: University Press, 1987.

34. Braveman PA, Cubbin C, Egerter $S$ et al. Socioeconomic status in health research-one size does not fit all. JAMA 2005;294:2879-2888.

35. Winker MA. Measuring race and ethnicity: Why and how? JAMA 2004;292:1612-1614.

36. Kaufman JS, Cooper RS, McGee DL. Socioeconomic status and health in blacks and whites: The problem of residual confounding and the resiliency of race. Epidemiology 1997;8:621-628.

37. Williams DR. Race/ethnicity and socioeconomic status: Measurement and methodological issues. Int J Health Serv 1996;26:483-505.

38. Williams DR, Collins C. Racial residential segregation: A fundamental cause of racial disparities in health. Public Health Rep 2001;116:404-416.

39. Braveman P, Cubbin C, Marchi K et al. Measuring socioeconomic status/ position in studies of racial/ethnic disparities: Maternal and infant health. Public Health Rep 2001;116:449-463.
40. Meier-Kriesche HU, Ojo A, Magee JC et al. African-American renal transplant recipients experience decreased risk of death due to infection: Possible implications for immunosuppressive strategies. Transplantation 2000;70: $375-379$.

41. Miles CD, Schaubel DE, Jia X et al. Mortality experience in recipients undergoing repeat transplantation with expanded criteria donor and nonECD deceased-donor kidneys. Am J Transplant 2007;7:1140-1147.

42. Rhee CM, Lertdumrongluk P, Streja E et al. Impact of age, race and ethnicity on dialysis patient survival and kidney transplantation disparities. Am J Nephrol 2014;39:183-194.

43. Peralta CA, Risch N, Lin F et al. The association of African ancestry and elevated creatinine in the Coronary Artery Risk Development in Young Adults (CARDIA) Study. Am J Nephrol 2010;31:202-208.

44. Kerman RH, Kimball PM, Vanburen CT et al. Possible contribution of pretransplant immune responder status to renal-allograft survival differences of black versus white recipients. Transplantation 1991;51:338-342.

45. Gaston RS, Hudson SL, Deierhoi MH et al. Improved survival of primary cadaveric renal-allografts in blacks with quadruple immunosuppression. Transplantation 1992;53:103-109.

46. Neylan JF. Immunosuppressive therapy in high-risk transplant patientsdose-dependent efficacy of mycophenolate mofetil in African-American renal allograft recipients. Transplantation 1997;64:1277-1282.

47. Ojo AO, Port FK, Held PJ et al. Inferior outcome of 2-haplotype matched renal-transplants in blacks-role of early rejection. Kidney Int 1995;48:1592-1599.

48. Yan G, Norris KC, Yu AJ et al. The relationship of age, race, and ethnicity with survival in dialysis patients. Clin J Am Soc Nephrol 2013;8:953-961.

49. Whittle JC, Whelton PK, Seidler AJ et al. Does racial variation in risk factors explain black-white differences in the incidence of hypertensive endstage renal disease? Arch Intern Med 1991;151:1359-1364.

50. McClellan W, Tuttle E, Issa A. Racial differences in the incidence of hypertensive end-stage renal disease (ESRD) are not entirely explained by differences in the prevalence of hypertension. Am J Kidney Dis 1988;12:285-290.

\section{SUPPORTING INFORMATION}

Additional Supporting Information may be found in the online version of this article:

Table S1 Complete Case Analysis for Sensitivity Analysis: Unadjusted and Adjusted Hazard Ratios for Death and Graft Failure in Elderly ( $\geq 60)$ Renal Transplant Recipients from July 1996 to October 2010 According to Race and Ethnicity

Table S2 Adjusted Hazard of Death and Graft Failure in Elderly $(\geq 60)$ Renal Transplant Recipients from July 1996 to October 2010 According to Race and Ethnicity Stratified According to Age

Please note: Wiley-Blackwell is not responsible for the content, accuracy, errors, or functionality of any supporting materials supplied by the authors. Any queries (other than missing material) should be directed to the corresponding author for the article. 